\title{
Outcomes of Open Cystolithotomy and Percutaneous Cystolithotripsy in the Management of Urinary Bladder Stone
}

\author{
Shrestha NM
}

\begin{abstract}
Introduction: Urinary bladder stone occupies only $5 \%$ of all urinary tract stone. Various techniques have been used for the management of bladder stone. Open Cystolithotomy is the traditional treatment but a percutaneous approach has been also in practice. Aims: To confirm the best options between open cystolithotomy and percutaneous cystolithotripsy for the treatment of bladder stone. Methods: It is a prospective hospital based study from May 2019 to January 2021 in Nepalgunj Medical College. Total 42 patients with inclusion criteria were divided into two groups. Group I was allocated to 21 patients who were treated with open cystolithotomy while Group II were allocated to 21 patients who were treated with percutaneous cystolithotripsy. Two groups were compared for stone free rate, mean hospital stay, mean postoperative scar, mean operation time and rate of post-operative complications. Results: The stone free rate in Group I was $100 \%$ and in Group II was $90.47 \%$. Mean Operation time was in Group I and Group II were 40.09+ 2.48 minutes and 31.38+15.65 days, respectively with $p<0.05$. Mean hospital stay was significantly low in Group II (3.71 \pm 1.87 days ) when compared to Group I ( $7.67 \pm 2.12$ days) with $p<0.001$. Mean scar length of Group I $(5.466 \pm 2.9 \mathrm{~cm})$ with respect to Group II $(1.04 \pm 0.09)$ was significantly long $(p<0.01)$. Rate of complications were not significantly different between two groups $(\mathrm{p}>0.5)$. Conclusion: For management of urinary bladder stones sized up to $4 \mathrm{~cm}$, both open cystolithotomy and percutaneous cystolithotripsyare effective, with a low incidence of complications. However, comparing the surgery time, hospital stay, length of scar between two procedures, percutaneous cystolithotripsy procedure is more beneficial for treatment of urinary bladder stone.
\end{abstract}

Keywords: Open cystolithotomy, Percutaneous cystolithototripsy, Urinary bladder

Author:

1. Dr. Naresh Man Shrestha

\section{Address for Correspondence:}

Dr. Naresh Man Shrestha

Associate Professor

Department of Uro-Surgery

Nepalgunj Medical College and Teaching Hospital

Kohalpur, Banke

Email: drnms1973@gmail.com

\section{INTRODUCTION}

Bladder stones constitute approximately $5 \%$ of all urinary tract stones. ${ }^{1}$ This disease is more prevalent in children, especially in developing countries due to poor nutrition and in adults it is commonly due to bladder outlet obstruction, chronic infection and the presence of an intravesical foreign body. The male femaleratio of bladder stones is 10:1 to 4:1. The incidence peaks at three years in children in developing countries, and 60 years in adulthood..$^{2-6}$ Bladder stones may be asymptomatic. However, symptoms such as suprapubic pain, irritative, obstructive features and renal failure may occur in over $50 \%$ of patients. ${ }^{7,8}$ Various techniques have been used for the management of bladder stone. Open suprapubic cystolithotomy (OCL) has been the standard surgery. ${ }^{9}, 10$ However, patients with bladder stone can have high chances of recurrence therefore second open surgery becomes technically difficult. Other newer endoscopic surgery are in practice such as, percutaneous cystolithotrypsy ( $P C C L)$, transurethral cystolithotrypsy (TUCL) and Extra corporeal shock wave lithotripsy (ESWL) in which no technical difficulty is found to remove the stone which is reoccurred. However, the efficacy of these procedures is depended on the size, and hardness of the stone. PCCL is well established technique with high efficacy and fewer complication than TUCL, specially treating larger stone. ${ }^{11,12}$ Therefore our aim is to evaluate the best options between OCL and PCCL for the treatment of bladder stone.

\section{METHODS}

It is prospective hospital based study conducted at Department of Urology, Nepalgunj Medical College, Kohalpur, from May 2019 - January 2021. Approval of Institutional Review Committee was obtained. Written informed consent was taken with explanation of risks and benefits of the procedure to the patient and family.

\section{Preoperative evaluation}

Patients with single stone size up to $4 \mathrm{~cm}$ with age 3- 60 years of any gender were included in this study. Patients with multiple stones, stone sized more than $4 \mathrm{~cm}$, stone with urinary bladder tumor and previous history of open cystolithotomy were excluded. Patients who fulfilled the inclusion criteria, 
were randomly selected according to lottery system to form two groups. Each group consisted 21 patients. Group I was allocated to patients who were treated with OCL while Group II was allocated to patients who were treated with PCCL.

Patients were studied for clinical history, clinical examinations. Further ultrasonography, Kidney-ureter-bladder (KUB) x-ray done and cystoscopy were done to establish diagnosis. After establishing diagnosis, routine laboratory investigations were done to perform surgery.

Outcomes were observed in terms of stone free rate, mean hospital stay (days), mean postoperative scar $(\mathrm{cm})$, mean operation time (minute) and rate of post - operative complications like intra peritoneal perforation, Surgical site infection and posterior bladder wall injury. Operative time is defined as total time taken (in minute) from starting of incision to closer of skin.

Hospital stay is defined as the period (day) from $1^{\text {st }}$ postoperative day to the day that patient is discharged. Stone free rate is defined as complete absence of stone in bladder. Postoperative scar length is defined as length $(\mathrm{cm})$ of wound made for the surgery. Complications rate is defined as unwanted result seen during and after surgery.

\section{Operative Technique}

OCL was performed under spinal anesthesia. Bladder was distended by filling with normal saline through Foley catheter. Pfanenstial incision was made, layer by layer reached up to urinary bladder. Peritoneum shifted to superiorly to prevent its injury. Bladder was opened, stone removed, perivesical drain was placed. Urinary bladder was closed in 2 layers. Catheter was removed in $6^{\text {th }}$ days and in next day drain and stitches were removed when no urinary leakage found from drain and the patient was discharged.

PCCL- PCCL also was performed under spinal anesthesia. Urinary bladder got distended by filling with normal saline through Foleys catheter. 2 fingers above from upper edge of pubic symphysis, approximately $1 \mathrm{~cm}$ incision was made. Then urinary bladder was punctured with puncture needle, guide wire placed through the needle, removed puncture needle .Tract was dilated, amplatz sheath of $28 \mathrm{Fr}$ placed. After removing all dilators, inserted 26 Fr Nephroscope. Under direct vision, stone got fragmented with pneumatic lithtriptor, all fragments removed. At last skin was closed with one stitch. In second post-operative day, removed catheter and in $3^{\text {rd }}$ post-operative day discharged with advice to remove suture in 7thpost-operative day in their own nearby hospital or medical center.

\section{Statistical analysis}

Data analysis was performed with the program statistical package for social sciences (SPSS version 17.0). Quantitative variables such as age, surgery time, length of hospitalization, scar length and stone size were expressed as mean \pm standard deviation (SD) whereas the qualitative variables such as stone clearance, gender, complication were presented as frequency and percentage. For analysis of quantitative variables, Independent sample t-test or Mann-Whitney $U$ test was used and for qualitative variable chi-square test was used. A p-value less than 0.05 was considered statistically significant.

\section{RESULTS}

Baseline characteristics of two categorized groups of patients with respect to age, stone size and gender were compared and found to be statistically non-significant $(p>0.05)$ as shown in Table I.

\begin{tabular}{|c|c|c|c|}
\hline Variables & Group I & Group II & P-value \\
\hline $\begin{array}{l}\text { Age } \\
\text { SD }\end{array}$ & $\begin{array}{c}31.62 \\
+20.607\end{array}$ & $\begin{array}{c}24.90 \\
+17.78\end{array}$ & 0.265 \\
\hline $\begin{array}{l}\text { Size of stone } \\
\text { SD }\end{array}$ & $\begin{array}{c}2.93 \\
\pm 0.63\end{array}$ & $\begin{array}{c}2.83 \\
\pm 0.55\end{array}$ & 0.623 \\
\hline $\begin{array}{l}\text { Gender } \\
\text { male:female }\end{array}$ & $16: 5$ & $14: 7$ & 0.495 \\
\hline
\end{tabular}

Table I: Baseline characteristics of the patients in Group I (OCL) and Group II (PCCL)

In Group II the mean operation time, mean hospital stay and the length of post-operative scar were significantly difference $(p<0.05)$ whereas stone free rate and rate of post-operative complications like surgical site infection, intraperitoneal rupture with gross extravasation of fluid and posterior bladder wall injury were statistically non-significant between two groups ( $p>0.05)$.

\begin{tabular}{|lccc}
\multicolumn{1}{r}{ Variables } & Group I & Group II & P- value \\
\hline Surgery time (min) & $40.09+2$ & 31.38 & $0.016^{*}$ \\
\hline Hospital stay(days) & 7.67 & 3.71 & $0.000^{*}$ \\
\hline Scar length (cm) & 5.466 & 1.104 & $0.001^{*}$ \\
\hline Complications (\%) & 9.52 & 14.28 & 0.634 \\
\hline Stone clearance (\%) & 100 & 90.47 & 0.147
\end{tabular}

*Statistically significantly

Table II: Comparison of mean surgery time, mean hospital stay, mean scar length, complications rate and stone free rate between Group I (OCL) and Group II (PCCL)

\begin{tabular}{ccc}
\hline Variables & Group I & Group II \\
\hline Surgical site infection (\%) & 2 & 0 \\
& $(9.52 \%)$ & $(0 \%)$ \\
\hline $\begin{array}{c}\text { Intraperitoneal rupture with gross } \\
\text { extravasation of fluid (\%) }\end{array}$ & 0 & 1 \\
Mild posterior bladder wall injury (\%) & $(\%)$ & $(4.76 \%)$ \\
\hline
\end{tabular}

Table III: Comparison of surgical complications in Group I and Group II 


\section{DISCUSSION}

Various techniques have been used for the management of urinary bladder stone. For removal of larger sized urinary bladder stone OCL or PCCL can be followed. However, patients with bladder stone can have high chances of recurrence of stone. Therefore, second open surgery becomes technically difficult in patient who underwent $O C L$ while PCCL there is no technical difficulty to remove the reoccurred stone. However, the efficacy of PCCL is depended on the size, and hardness of the stone and in such case the procedure may has to convert to OCL. Consequently, hospital stay, mean operation time and chances of complications increases in PCCL. Ourpresent study showed $100 \%$ stone free rate in OCL group and $90.47 \%$ in PCCL group however the difference was not significant. Similarly the study of Fabio et al ${ }^{14}$ showed that open surgery was $100 \%$ effective for removal of bladder stone. However studies of Wollin et $\mathrm{al}^{15}$, Demeriel et $\mathrm{al}^{16}$ reported $100 \%$ patients were free of stone following PCCL.

In our study mean operation time was shorter in PCCL group than OCL group which is supported by the study of Liu G et al. ${ }^{17}$ Meanwhile, two patients in PCCL group procedure was converted to $\mathrm{OCL}$ due to harder and big stone and mean operation time of those patients were 80 minutes and 75 minutes.Similarly, the study of J Babak et al ${ }^{18}$ the surgery time in OCL is 26.06 minutes and PCCL is 30.54 minutes for harder and multiple stone. About hospital stay as reported by the

study of Donaldson et $\mathrm{al}^{19}$ and Liu G et $\mathrm{al}^{17}$ mean hospital stay in OCL group was found to be longer than PCCL group. These findings were consistent with the results of our studies. This outcomes of the present study with respect to scar length in patient treated form OCL was longer than in patient treated form PCCL. The study Milind et $\mathrm{al}^{20}$ mentioned that the length of scar present in patients in PCCL was equal to diameter of amplatz sheath (20 fr) was $7 \mathrm{~mm}$ which concluded another major cosmetic advantage of PCCL. The present study encountered 2(9.52\%) cases of surgical site infection in OCL group whereas no such infection was found in PCCL Group. While the study of Liu G et al $^{17}$ reported 5 out of 25 patients (20\%) have surgical site infection in OCL. Our study further reported about 1 case of intraperitoneal bladder rupture with fluid leakage (4.76\%) and 2 cases of mild posterior bladder wall injury (9.52 \%) in PCCL group but such complications were not found in OCL group. Study of Al-marhoon et al Revealed small bowl injury in one child while intraperotenial bladder injury in 3 children in open surgery and further reported that one child had continuous urinary leakage from the site of operation in PCCL group. ${ }^{18}$

\section{LIMITATIONS}

There are different other modalities of endoscopic managements like transurethral cystolithitripsy, ESWL, however this study has considered only PCCL. Another limitation is the sample size which is very small.

\section{CONCLUSION}

For management of urinary bladder stones sized up to $4 \mathrm{~cm}$, both open cystolithotomy and percutaneous cystolithotomy are effective, with a low incidence of complications. However, comparing the surgery time, hospital stay, length of scar between two procedures, percutaneous cystolithotomy procedure is more beneficial for treatment of urinary bladder stone.

\section{REFERENCES}

1. Schwartz B.F.The vesical calculus.UrolClin North Am.2000; 27: 333. https://www.ncbi.nlm.nih.gov/pubmed/10778475

2. Schwartz BF, Stoller ML.The vesical calculus.UrolClin North Am. 2000;27(2):33346.

3. Yoshida O, Okada Y. Epidemiology of urolithiasis in Japan: a chronological and geographical study. Urol Int. 1990;45(2):10411.

4. Halstead, S.B. Epidemiology of bladder stone of children: precipitating events. Urolithiasis. 2016;44: 101.

5. Takasaki, E. Chemical compositions of 300 lower urinary tract calculi and associated disorders in the urinary tract. Urol Int. 1995; 54: 89.

6. Naqvi, S.A.Bladder stone disease in children: clinical studies. J Pak Med Assoc. 1984; 34: 94.

7. Menon M, Resnick MI. Urinary lithiasis: etiology, diagnosis, and medical management. In: Walsh PC, RetikAB,Vaughan ED, Wein AJ, editors. Campell's urology. $8{ }^{\text {th }}$ ed. Philadelphia: Saunders Elvesier.2004; p.3229.

8. Papatsoris AG, Varkarakis I, Dellis A, Deliveliotis C. Bladder lithiasis: from open surgery to lithotripsy. Urol Res. 2006;34(3):1637.

9. Bastug F, Gunduz Z, Tulper S, Poyrazoglu H, Dusungel R. Urolithiasis ininfants: Evaluation of risk factors. World J Urol.2012;1:19.

10. Zargooshi J. Open stone surgery in children: Is it justified in the era ofminimally invasive therapies? BJU Int.2001;88:92831.

11. Aron M, AgarwalMS, Goel A. comparision of percutaneous with Transurethral cystolithotripsy in patients with large prostate and large vesicle calculus undergoing simultaneous Transurethral prostatectomy.BJU Int.2003;91(3):293-5

12. Bulow $H$,FrohmullerHG.Electrohydrolic lithotripsy with aspiration of the fragments under vision-304consecutive cases.J.Urol.19810ct;126(4):454-6

13. Marusteri M,BacareaV.comparing groups for statistical difference:how to choose the right statistical test ? Biochemia Medica.2010;20(1):15-32

14. Torricelli FC, MazzucchiE, Dailvic A et al.surgical management of bladder stone : literaturw review.2013May/June;40(3). https:oi.org/10.1590/s0100-69912013000300011

15. Wollin TA, Singal RK, Whelan T, Dicecco R, Razvi HA, Denstedt JD. Percutaneous suprapubiccystolithotripsy for treatment 
of large bladder calculi. J Endourol. 1999;13(10):739-44

16. Demirel F, Cakan M, Yalçinkaya F, Demirel AC, Aygün A, Altuð UU. Percutaneous suprapubiccystolithotripsy approach: for whom? Why? J Endourol. 2006;20(6):429-31.

17. Liu G, Deng Y, Zhang S et al. Minimally invasive percutaneous suprapubiccystolithotripsy: an effective treatment for bladder stones with urethral strictures. Int J ClinExp Med.2016;9(10):19907-12

18. Javanmard B, Karkan MF, Razzaghi MR et al. Surgical Management of Vesical Stones in Children: A Comparison Between Open Cystolithotomy, Percutaneous Cystolithotomy and Transurethral Cystolithotripsy With Holmium-YAG Laser. J Lasers Med Sci. 2018; 9(3): 183-187.

19. Donaldson, J.F., et al. Treatment of Bladder Stones in Adults and Children: A Systematic Review and Meta-analysis on Behalf of the European Association of Urology Urolithiasis Guideline Panel. Eur Urol. 2019; 76: 352.

20. Joshi MP, Ruturaj K, Pankaj C et.al. Percutaneous cystolithotripsy in children and its outcome: A single center enxerience. Indian J Child health. 2018; 5 (12):735-38. 